\title{
Terminologia da Radiação Solar: elaboração de um glossário bilíngue (português-francês)
}

\section{Terminology of Solar Radiation: development of a bilingual glossary (Portuguese-French)}

\author{
Renata Tonini Bastianello* \\ Adriana Zavaglia**
}

Resumo: Este artigo visa a descrever o processo de elaboração de um glossário bilíngue (português-francês) de termos da Radiação Solar, apresentando a compilação de um corpus de estudo especializado, a coleta de termos, a comparação de traços descritores na busca por equivalências e a redação da micro e macroestrutura da obra. A terminologia da Radiação Solar - subárea da Energia Solar Fotovoltaica - se caracteriza como multidisciplinar: possui termos próprios e termos emprestados de outros campos do conhecimento. Identificar essas unidades terminológicas e buscar seus equivalentes em outros idiomas para fins terminográficos são tarefas necessárias para auxiliar profissionais e aprendizes da área, assim como tradutores de documentos técnicos, pois, com o uso cada vez mais difundido da Energia Solar Fotovoltaica, a tradução de livros e manuais técnicos, de contratos e propagandas que trazem consigo termos da Radiação Solar começa a fazer parte das demandas de trabalho do tradutor brasileiro. Para este estudo, nos baseamos nos conceitos da Teoria Comunicativa da Terminologia (CABRÉ 1999), utilizamos ferramentas da Linguística de Corpus, especialmente o AntConc (ANTHONY 2014) e empregamos o método denominado Ganchos Terminológicos (DUBUC 1985) para a busca por relações de sinonímia e equivalência.

Palavras-chave: Tradução; Terminologia; Radiação Solar; Energia Solar Fotovoltaica; Glossário bilíngue.

Abstract: This article aims to describe the process of elaborating a bilingual (Portuguese-French) glossary of Solar Radiation terms, presenting the compilation of a

\footnotetext{
* Doutoranda do Programa de Estudos Linguísticos, Literários e Tradutológicos em Francês do Departamento de Letras Modernas da Faculdade de Filosofia, Letras e Ciências Humanas da Universidade de São Paulo. E-mail: bastianello@usp.br.

** Docente do Departamento de Letras Modernas da Faculdade de Filosofia, Letras e Ciências Humanas da Universidade de São Paulo. E-mail: zavaglia@usp.br.
} 
specialized corpus of study, the collection of terms, the comparison of descriptive traits in the search for equivalences and the writing of the micro and macrostructure of the dictionary. The terminology of Solar Radiation - subarea of Photovoltaic Solar Energy - is characterized as multidisciplinary: it has its own terms and also terms borrowed from other fields of knowledge. Identifying these terminological units and searching for their equivalents in other languages for terminological purposes are necessary tasks to assist professionals and apprentices of the field, as well as translators of technical documents, since, with the increasingly widespread use of Photovoltaic Solar Energy, the translation of books and technical manuals, contracts and advertisements - which bring with them Solar Radiation terms, begin to be part of the works demand of the Brazilian translator. For this study, we used the concepts of the Communicative Theory of Terminology (CABRÉ 1999), the tools of Corpus Linguistics, specially AntConc (ANTHONY 2014) and the method called textual matches (DUBUC 1985) to search for synonymy and equivalence relations.

Keywords: Translation; Terminology; Solar Radiation; Photovoltaic Solar Energy; Bilingual glossary. 


\section{Introdução}

O Brasil é um país privilegiado, com um vasto potencial energético, e capaz de produzir energia elétrica a partir de diferentes fontes renováveis inesgotáveis e pouco poluentes. Cerca de $60 \%$ da eletricidade do país provêm de usinas hidrelétricas, que utilizam a água como fonte combustível. No entanto, parques eólicos e centrais solares que aproveitam, respectivamente, os ventos e os raios solares para gerar energia vêm ganhando espaço na diversificação da matriz energética brasileira.

A Energia Solar Fotovoltaica (doravante ESF) é a transformação direta dos raios solares em energia elétrica. Nesse processo, a energia do Sol é captada por dispositivos chamados de painéis solares (Figura 1), que, através do efeito fotovoltaico, são os responsáveis por obter eletricidade. Apesar do constante crescimento do emprego da ESF nas últimas décadas, o alto preço dos equipamentos é, ainda, um empecilho para uma maior difusão do seu uso.

Figura 1: Conjunto de painéis solares fotovoltaicos de silício.

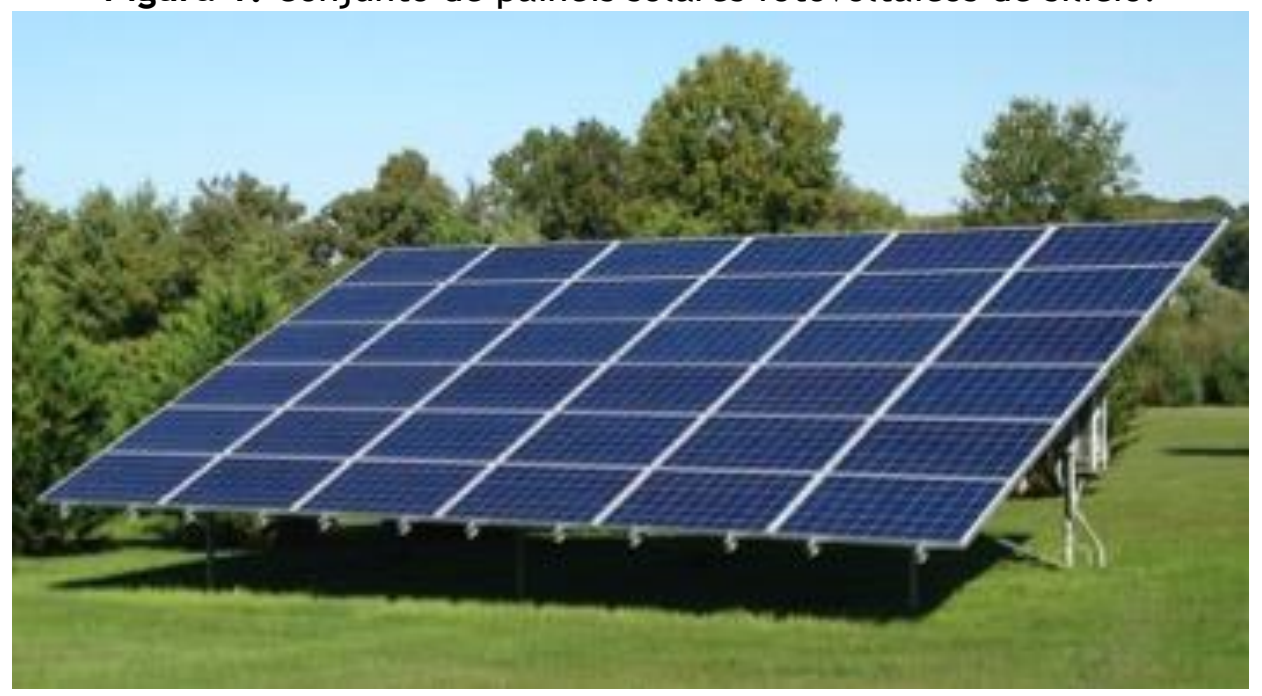

Fonte: KW Solar Solutions, 2018.

Uma das dificuldades enfrentadas pelos especialistas da área é a questão da eficiência dos painéis solares ${ }^{1}$. Grande parte da energia solar que chega até

\footnotetext{
${ }^{1}$ De forma simplificada, a eficiência de um painel é a quantidade de luz solar que ele é capaz de converter em energia elétrica por metro quadrado e seu valor é medido em porcentagem (PORTAL SOLAR 2018).
}

TradTerm, São Paulo, v. 34, outubro/2019, p. 27-47 
os painéis não é aproveitada devido a "limitações da tecnologia e perdas inerentes ao processo" (ZILLES ET AL. 2012: 30). Assim, podemos afirmar que um painel de maior eficiência gera mais eletricidade em comparação a um painel menos eficiente exposto à mesma quantidade de luz. No entanto, a eficiência ainda se encontra diretamente ligada ao custo do painel: materiais mais eficientes são mais caros.

Com o intuito de aproveitar ao máximo a capacidade de geração de um painel, é importante expor o painel à maior quantidade de luz solar possível, ou seja, antes de realizar a instalação de um painel, deve-se observar seu posicionamento ideal. Segundo estudos realizados, um painel utilizado no hemisfério sul deve ser direcionado para o norte e seu ângulo, em relação ao solo, não deve ser menor que a latitude do local (PORTAL SOLAR 2018; STROM BRASIL 2018). Vejamos, na Figura 2, a ilustração de Villalva e Gazoli (2012), que mostra a incidência dos raios solares na superfície do painel para diferentes ângulos de inclinação:

Figura 2: Efeito da inclinação do painel solar na captação de energia.
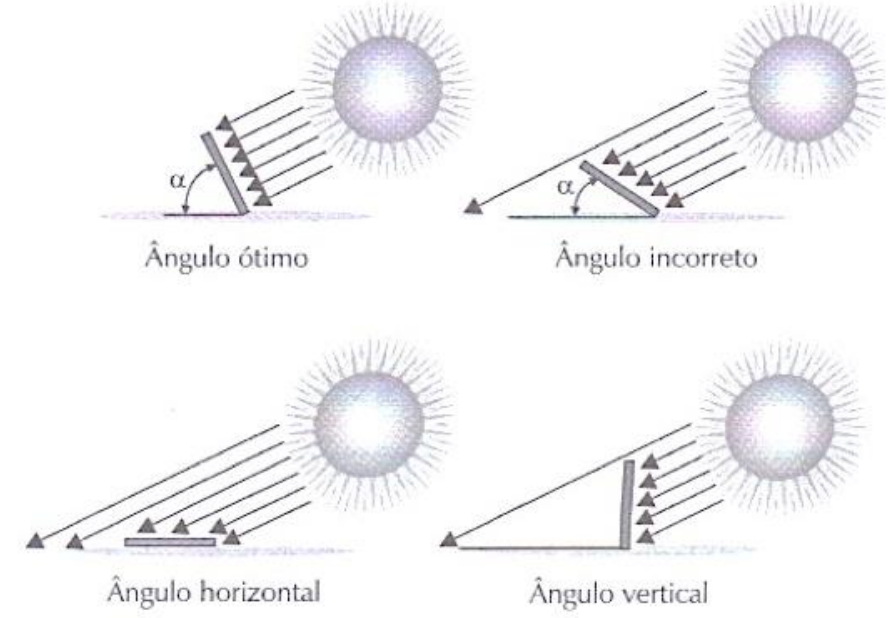

Fonte: Villalva e Gazoli, 2012.

Conforme brevemente caracterizado, realizar o cálculo do posicionamento ideal de um painel solar envolve o conhecimento de conceitos trazidos de várias áreas do conhecimento, como a física, a geografia, entre outras, dentre os quais o de "radiação solar direta" e "radiação solar difusa", "insolação", "latitude”, “longitude”, "hemisfério norte”, "hemisfério sul”, "massa de ar", "comprimento de onda", "ângulo azimutal”, "albedo" etc. 
Dessa forma, textos (livros, materiais didáticos e outros) e cursos de ESF possuem, em geral, um capítulo ou um módulo que trata de conceitos básicos, que chamaremos aqui de Radiação Solar.

Desse modo, observamos que materiais de referência da ESF abordam essa questão. No Brasil, Villalva e Gazoli (2012), por exemplo, têm seu segundo capítulo intitulado “Conceitos Básicos”, com os seguintes tópicos: 2.1 Radiação Solar; 2.2 Massa de ar; 2.3 Tipos de radiação solar; 2.4 Energia solar; 2.4.1 Irradiância; 2.4.2 Insolação; 2.5 Orientação dos módulos fotovoltaicos; 2.6 Ângulo azimutal; 2.7 Movimento da Terra; 2.8 Declinação solar; 2.9 Altura solar; 2.10 Ângulo de incidência dos raios solares. Da mesma forma, Na França, Labouret et al. (2010) denominam seu segundo capítulo Ensoleillement et lumière, composto pelos seguintes itens: 2.1 Qu'est-ce que la lumière?; 2.2 Le rayonnement solaire; 2.3 Les sources de lumière artificielles.

Como a grande maioria dos documentos de referência sobre a ESF dedicase em parte aos estudos da Radiação Solar, identificamos a importância desta área para o estudo da ESF, interesse de nossa pesquisa².

Para dar conta de descrever e analisar essa terminologia específica de base dentro de um contexto de pesquisa mais geral sobre a ESF (V. nota ii), reunimos um corpus de estudo comparável bilíngue (português-francês) para a coleta e análise das unidades terminológicas da Radiação Solar. Nossa finalidade é elaborar uma pequena obra terminográfica composta de termos, sinônimos e equivalentes que possa servir de auxílio não apenas aos aprendizes, profissionais e tradutores da área da ESF, caso de nossa pesquisa, mas também àqueles que se veem às voltas com essa terminologia em áreas afins. Essa obra, realizada à luz da Teoria Comunicativa da Terminologia (CABRÉ 1999) e das ferramentas da Linguística de Corpus (TAGnin 2013; Berber SARdinha 1999; ANTHONY 2014), será disponibilizada gratuitamente em formato de e-book na Internet.

\footnotetext{
${ }^{2}$ Nosso foco de estudo é a Energia Solar Fotovoltaica, cuja terminologia estudamos em nossa pesquisa de mestrado. Assim, trataremos, aqui, a Radiação Solar como uma subárea da Energia Solar Fotovoltaica. Ver BASTIANELLO, R. T. Terminologia da energia solar fotovoltaica para fins terminográficos: estudo baseado em corpus comparável (português-francês). 2017. 378f. Dissertação (Mestrado) - Faculdade de Filosofia Letras e Ciências Humanas da Universidade de São Paulo, São Paulo, 2017. Disponível em:

<http://www.teses.usp.br/teses/disponiveis/8/8146/tde-11122017-190034/pt-br.php>. Acesso em: 01 maio 2018.
} 
Este artigo, que apresenta o processo de elaboração desse glossário, é subdividido, além desta introdução, em: referencial teórico, material e método (elaboração dos corpora, coleta dos termos e busca por equivalente e macro e microestrutura do glossário), análises e resultados, conclusão e referências.

\section{Referencial teórico}

Para apresentarmos a elaboração de um glossário da terminologia da Radiação Solar realizado a partir dos preceitos da Teoria Comunicativa da Terminologia (CABRÉ 1999), abordaremos brevemente nesta seção alguns pontos significativos da pesquisa. ${ }^{3}$ Terminologia é uma palavra que pode ser considerada polissêmica (KRIEGER; FinatTo 2015). Em uma primeira acepção, geralmente grafada com "t" minúsculo, é um "conjunto de termos". Podemos dizer que a comunicação entre especialistas de uma área do conhecimento, ao tratar de seu objeto de trabalho, envolve, sempre, a terminologia da área. Assim, cada atividade humana, seja ela qual for - uma ciência, uma técnica etc. - , possui a sua terminologia própria: o conjunto de termos utilizados para nomear seus conceitos e transmitir seus conhecimentos.

No entanto, Terminologia, quando escrita com "T" maiúsculo, é a ciência que estuda os termos e as linguagens de especialidade. Foi Eugen Wüster, nos anos 1970, quem conseguiu firmar a Terminologia como uma disciplina independente, através da Teoria Geral da Terminologia - TGT. De caráter onomasiológico, partindo do conceito para o termo, essa abordagem possuía finalidade normalizadora e padronizadora, buscando uma linguagem técnicocientífica livre das imprecisões, polissemias, sinonímias e homonímias existentes na língua geral (WüsTER 1998).

Com o avanço da ciência e da tecnologia, os termos proliferaram-se para além do campo técnico e, sem desconsiderar as contribuições da TGT, novas abordagens teóricas foram criadas. No início dos anos 1990, Maria Teresa Cabré propôs a Teoria Comunicativa da Terminologia - TCT. Partindo de uma perspectiva de comunicação real, a TCT se fundamenta nas teorias do

\footnotetext{
3 Para uma explicação detalhada da área da Linguística de Corpus e dos ganchos terminológicos, Ver: BASTIANELLO (2017).
}

TradTerm, São Paulo, v. 34, outubro/2019, p. 27-47 
conhecimento, da comunicação e da linguagem, ou seja, ela não se prende apenas aos aspectos linguísticos da comunicação especializada (CABRÉ 1999).

Nesse sentido, Cabré (1999: 123) explica que unidades lexicais são apenas "potencialmente termos ou não-termos", havendo, então, a necessidade de analisar uma série de "traços semânticos e pragmáticos específicos que descrevem seu caráter de termo dentro de um determinado âmbito". Assim, os termos existem apenas quando inseridos dentro de um contexto, eles são:

em princípio, unidades léxicas que fazem parte do léxico do falante e que adquirem valor especializado de acordo com seu uso em determinado âmbito especializado (BEVILACQUA 1998: 3).

De forma análoga, Anna Maria Maciel (MACIEL 2001: 41) comenta que o léxico comum pode ganhar o status de termo dentro de um contexto especializado, assim como um termo pode ser criado de forma independente desde que sejam seguidas as regras da língua:

Ainda que primitivamente originários do acervo do léxico geral, ou criados de acordo com as mesmas regras obedecidas no processo de construção do léxico comum, os termos começam a existir quando se unem indissoluvelmente a conceitos determinados dentro de um conjunto conceitual estruturado em uma área de especialidade. Só então, no interior desse sistema, as unidades lexicais se constituem em unidades terminológicas e passam a constituir uma terminologia. (MACIEL 2001: 41)

Para fins de exemplificação, analisaremos, a seguir, a lexia "raio". Vejamos parte de seu verbete, retirado do dicionário on-line Aulete Digital (2018): 
Quadro 1: Verbete (adaptado) de "raio".

\section{(rai.o)}

sm.

1. Fís. Feixe de luz ou de outra forma de energia radiante (raios do sol; raio de luz).

2. Descarga elétrica no espaço, seguida de relâmpago: Ontem à noite, caiu uma tempestade com muitos raios.

3. Fís. Movimento retilíneo por meio do qual se propagam as radiações (raio alfa; raio beta; raio gama).

4. Geom. Distância do centro de circunferência ou de esfera a qualquer de seus pontos, meio diâmetro da circunferência.

8. Fig. Sinal, mostra, indício (raio de esperança).

9. Fig. Pop. Espécie, tipo: Que raio de coisa é essa?

10. Jur. Perímetro onde determinada coisa se localiza e que se constitui o seu limite.

Fonte: Aulete Digital, 2018.

No Quadro 1, há diferentes acepções para “raio” e diversas rubricas. A acepção 2, "Descarga elétrica”, não possui rubrica, ou seja, faz parte da língua geral e é de conhecimento de falantes do idioma. Da mesma forma, as acepções 8 e 9 também fazem parte da língua geral e as rubricas à qual pertencem (Figurado e Figurado Popular) indicam, apenas, que a lexia está sendo utilizada em sentido figurado, isto é, com um sentido alterado do seu significado primeiro.

As demais acepções do verbete, de maior interesse para nós, possuem rubricas de especialidade: Física, Geometria e Jurídico. Observamos, então, que a palavra "raio" adquire outro valor - um valor especializado - dentro de certas áreas do conhecimento. É possível notar, ainda, que, no caso da Física, a mesma denominação serve para designar dois conceitos distintos, "feixe de luz" e "movimento retilíneo". Confirmamos, assim, a existência de polissemia dentro de uma mesma linguagem de especialidade (raio como designação do conceito "feixe de luz" e como designação do conceito "movimento retilíneo") e da sinonímia ("raio" e "feixe de luz", por exemplo, podem ocorrer num mesmo texto remetendo a um mesmo conceito).

Segundo Cabré (1999: 122), a sinonímia é "um fenômeno real dentro da comunicação especializada natural”. A TCT possui, inclusive, o "Princípio sobre a variação", postulando que os termos podem sofrer tanto variação denominativa (sinonímia) quanto variação conceitual (polissemia): 
Todo processo de comunicação comporta, inerentemente, variação, explicitada por formas alternativas de denominação do mesmo conceito (sinonímia) ou por abertura significativa de uma mesma forma (polissemia). Este princípio é universal para as unidades terminológicas, embora admita diferentes graus segundo as condições de cada tipo de situação comunicativa (CABRÉ 1999: 85).

Assim, considerando os pressupostos da TCT expostos acima, principalmente no que diz respeito ao tratamento dos termos como unidades existentes apenas dentro de um contexto específico e passíveis de relações sinonímicas nesse mesmo contexto, escolhemos utilizar essa abordagem teórica na busca e análise de termos da Radiação Solar. Sua terminologia apresenta diversos casos de cuja descrição a TCT é capaz de dar conta, como veremos na próxima seção.

\section{Material e método}

A metodologia utilizada para a elaboração do glossário de Radiação Solar possui quatro etapas: 1) sistematização do corpus de estudo e seleção dos corpora de referência; 2 ) análise do corpus de estudo para a coleta de termos; 3) análise dos ganchos terminológicos na busca por equivalentes portuguêsfrancês; e 4) redação do glossário. Detalharemos, a seguir, cada uma dessas etapas e os materiais empregados para realizá-las.

\subsection{Elaboração dos corpora}

Utilizamos um corpus de estudo, elaborado por nós, e dois corpora de referência. O corpus de estudo abrangeu a temática Radiação Solar e foi do tipo comparável português-francês, ou seja, foi composto por textos escritos originalmente em português do Brasil e originalmente em francês da França. Para tanto, nos valemos de quatro livros de Energia Solar Fotovoltaica ${ }^{4}$, dois

\footnotetext{
${ }^{4}$ Os livros utilizados para a compilação do corpus de estudo foram os seguintes: ALAIN, R. Les convertisseurs photovoltaïques: gisement solaire, cellules, modules et champs de modules.
}

TradTerm, São Paulo, v. 34, outubro/2019, p. 27-47 
em cada idioma, escritos por especialistas na área; desses livros, utilizamos para o corpus apenas a seção de Radiação Solar, totalizando, assim, cerca de 5,5 mil palavras (tokens) para cada idioma de estudo. 0 corpus compilado é de tamanho pequeno, mas podemos considerá-lo de tamanho satisfatório para a coleta de termos desejada, uma vez que trouxe os resultados esperados - não sendo nosso objetivo realizar uma coleta de dados exaustiva (BERBER SARDINHA 2004).

Podemos dizer, ainda, que o corpus de estudo é do tipo sincrônico e estático, pois compreende um curto período de tempo (2010 a 2012) e não passou por modificações, além de ser escrito - sem o uso de transcrições - e não possuir anotações morfossintáticas. Não consideramos necessário o uso de anotações para este estudo, pois não foi nossa intenção analisar, por exemplo, questões categoriais. As características do corpus de estudo estão organizadas no Quadro 2:

Quadro 2: Resumo das características do corpus de estudo.

\begin{tabular}{ll}
\hline & \multicolumn{1}{c}{ Corpus de estudo } \\
\hline Tipo & Comparável \\
\hline Língua & Bilíngue português-francês \\
\hline Temática & Radiação Solar \\
\hline Autoria & Autores nativos e especialistas \\
\hline Modificações futuras & Estático \\
\hline Período de tempo & Sincrônico (2010-2012) \\
\hline Material & Escrito \\
\hline Etiquetagem & Não anotado \\
\hline Palavras por língua & $\approx 5,5$ mil \\
\hline
\end{tabular}

Para o emprego das ferramentas de análise da Linguística de Corpus, foi necessário, além do corpus de estudo, um corpus de referência para cada idioma envolvido na pesquisa. Dessa forma, para o português, utilizamos textos

Valbonne: CytheliA, 2012. LABOURET, A. ET AL. Cellules solaires: les bases de l'énergie photovoltaïque. 5 ed. Paris: Dunod, 2010. SANTOS, M. A. dos (org.). Fontes de Energia Nova e Renovável. Rio de Janeiro: LTC, 2012. VILLALVA, M. G.; GAZOLI, J. R. Energia Solar Fotovoltaica: conceitos e aplicações. São Paulo: Érica, 2012. 
de jornalismo retirados do Lácioweb/Lácio-Ref ${ }^{5}$ e, por não termos acesso a um corpus on-line de francês para usarmos como referência, compilamos um corpus de mesma temática - jornalismo -, através do BootCaT Frontend ${ }^{6}$ (versão 0.81 de 2016). Cada um desses corpora foi composto por cerca de 20 mil tokens.

sses corpora de referência, também chamados de corpora de controle (BERBER SARDINHA 1999), servem como contraponto. O corpus de referência deve ser composto, então, por textos da língua geral ou de alguma especialidade não contemplada no corpus de estudo e, para que sejam obtidos resultados satisfatórios, deve ser de três a cinco vezes maior que o corpus de estudo (TAGNIN 2013). Para fins de esclarecimento, vejamos a Figura 3:

Figura 3: Corpus de estudo (1), corpus de referência (2) e a intersecção entre eles (3).

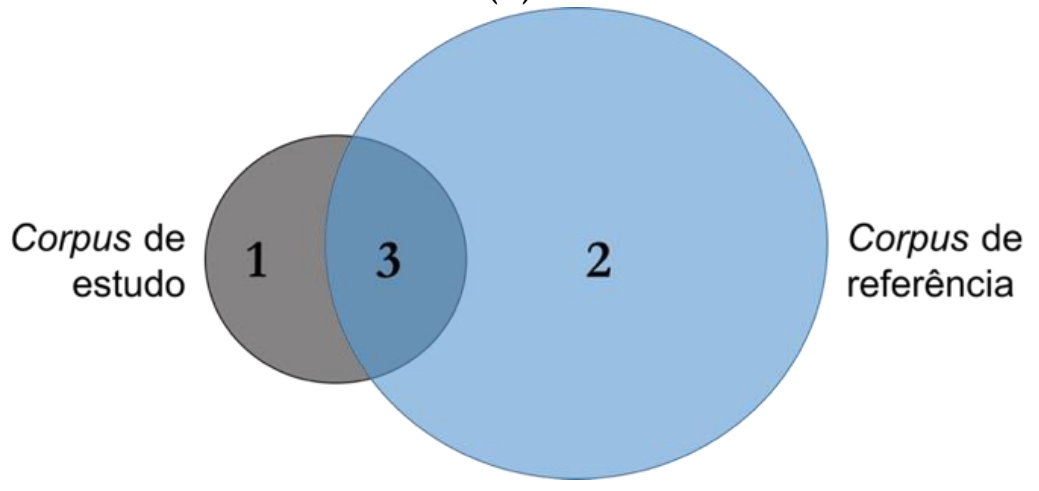

Como comentamos, neste estudo utilizamos corpora de referência com a temática jornalismo. A partir da Figura acima temos, então, o corpus de estudo (1) com a temática Radiação Solar e o de referência (2) dentro do domínio do jornalismo. Se colocarmos os corpora num software de análise linguística, este irá compará-los e verificará quais são as palavras que aparecem com a mesma frequência em ambos - representadas na Figura 3 pela área de intersecção (3). O software gerará, então, uma lista de palavras-chave do corpus de estudo, composta pelas palavras deste corpus menos aquelas presentes na área de intersecção (área cinza da figura), ou seja, aquelas que

\footnotetext{
${ }^{5}$ Corpus on-line, em português brasileiro, disponível para download gratuito. É dividido em quatro corpora e vários domínios. Disponível em: <http://143.107.183.175:22180/lacioweb/index.htm>. Acesso em: 30 jan. 2018.

${ }^{6}$ O BootCaT é um software livre com a capacidade de compilar corpora rapidamente. A partir de palavras-chave inseridas pelo usuário, o BootCaT retira textos de sites da Internet e os reúne em um único arquivo de texto (.txt). Disponível em: <http://bootcat.sslmit.unibo.it/>. Acesso em: 30 jan. 2018.
} 
sobressaem em chavicidade e que são candidatas a termo da área pesquisada. É a partir da lista de palavras-chave do corpus de estudo que identificamos, então, a terminologia da área, como descrito a seguir.

\subsection{Coleta dos termos}

Realizada a compilação dos corpora de estudo e de referência, partimos para as análises através do AntConc ${ }^{7}$. Para tanto, nos valemos de algumas importantes ferramentas disponibilizadas pelo programa: Word list, Keyword list e Concordance. 0 primeiro passo foi utilizar a Word list, ou Lista de palavras. Esta ferramenta gera duas listas com todas as palavras de cada um dos corpora em ordem de frequência crescente, ou seja, as palavras do topo da lista são aquelas que aparecem o maior número de vezes em cada um dos corpora.

A ferramenta Keyword list compara, estatisticamente, a lista de palavras do corpus de estudo com as do corpus de referência, produzindo uma lista das palavras mais relevantes do corpus de estudo: palavras que se destacam, estatisticamente, como mais frequentes. Essa lista de palavras-chave nos trouxe os candidatos a termo da Radiação Solar e serviu como base para a identificação dos termos.

Por fim, utilizamos o Concordance, ou Concordanciador, para gerar as concordâncias de cada palavra da lista de palavras-chave. As linhas de concordância correspondem às ocorrências da palavra em contexto, nos possibilitando verificar se a palavra é, de fato, um termo da área e se é um termo simples - uma única lexia; ou complexo - formado por duas ou mais unidades lexicais.

A análise da lista de palavras-chave e das concordâncias foi realizada de forma separada para cada idioma de estudo. Após a obtenção de uma lista de termos em português e uma em francês, partimos para a confrontação dos termos, na busca por equivalentes.

\footnotetext{
7 O AntConc (ANTHONY 2014) é um dos softwares mais utilizados atualmente para análise linguística. Concebido em 2004 por Laurence Anthony, o AntConc é gratuito e possui diversas ferramentas, como Keyword List e Concordance.
}

TradTerm, São Paulo, v. 34, outubro/2019, p. 27-47 


\subsection{Busca por equivalentes}

A busca por termos equivalentes português-francês foi realizada através da confrontação de ganchos terminológicos, ou crochets terminologiques traços descritores que podem ser encontrados, juntamente com as unidades terminológicas, em seus contextos. Dubuc (1985: 62) define os ganchos como sendo “elementos reveladores da noção contidos no contexto" e explica que “os [traços] descritores mais significativos são aqueles que exprimem natureza, finalidade e modo"8. Além desses ganchos, podemos encontrar outros, como o de material, oposição, característica, domínio, efeito, causa etc. (DuBuc 1985; AUBERT 2001).

A partir dos ganchos terminológicos, é possível verificar a relação de equivalência entre termos de línguas distintas, assim como a relação de sinonímia entre termos de um mesmo idioma. Dubuc (1985: 69) afirma que dois termos são equivalentes quando possuem uma “identidade completa de sentido e de usos dentro de um mesmo domínio de aplicação"9, ou seja, "devem designar o mesmo conceito e ser utilizados nas mesmas situações comunicativas" (BASTIANELLO 2017: 54).

Como exemplo prático da aplicação desse método, confrontemos os termos da Energia Solar Fotovoltaica "silício cristalino" e silicium cristallin". Para o primeiro termo, temos a seguinte linha de concordância: "As células de primeira geração, feitas a partir de silício cristalino, englobam as soluções monocristalinas e policristalinas". Nota-se que “células de primeira geração" é um gancho terminológico de natureza, enquanto que "monocristalinas e policristalinas" é um gancho de material. De forma análoga, temos o seguinte contexto, retirado do corpus em francês: 1ère génération : Silicium cristallin (mono et poly); Cette génération de cellule repose sur les wafers (fine tranches) de silicium cristallin. Temos, aqui, o mesmo gancho de natureza,

\footnotetext{
8 “[...] éléments révélateurs de la notion contenus dans le contexte. Les [traits] descripteurs les plus significatifs sont ceux qui expriment la nature, la fin et la manière".

9 “[...] identité à peu près complète de sens et d'usage à l'intérieur d'un même domaine d'application".

10 Exemplo retirado de Bastianello (2017).
}

TradTerm, São Paulo, v. 34, outubro/2019, p. 27-47 
1ère génération, e o mesmo gancho de material, mono et poly. Assim, é a partir da confrontação desses e de outros traços descritores que podemos confirmar a relação de equivalência entre termos. Esse processo de busca por ganchos foi realizado para cada um dos candidatos a termo recolhidos para compor a lista de termos.

\subsection{Macro e microestrutura do glossário}

O glossário aqui descrito possui uma macroestrutura ${ }^{11}$ simples, em que os termos foram organizados em ordem alfabética. São apresentados, primeiramente, os termos em português (no sentido do português para o francês) e, em seguida, os termos em francês (no sentido do francês para o português). Cada termo possui um verbete próprio.

Para a microestrutura ${ }^{12}$ do glossário, temos o termo como entrada, seguido por sua categoria gramatical e seu sinônimo, ou sinônimos, também com a indicação da categoria gramatical. 0 verbete é concluído com o equivalente em língua estrangeira - ou os equivalentes, quando houver mais de um. 0 quadro abaixo ilustra um exemplo de microestrutura do glossário:

Quadro 3: Exemplo de microestrutura do glossário.

termo em português. cat.gr.
(sinônimo(s) em português
cat.gr.). equivalente 1 em
francês (cat.gr.), equivalente 2
em francês (cat.gr.).

Nota-se, a partir do Quadro 3, que o termo em português (entrada) é negritado e destacado com um tamanho de fonte maior do que o restante do verbete. O sinônimo em português é apenas negritado, enquanto que os equivalentes 1 e 2 não o são. Além disso, a primeira linha, em que temos a

\footnotetext{
11 Para Rey-Debove (1971: 21), macroestrutura é "o conjunto das entradas ordenadas, sempre sujeita à leitura vertical parcial no momento da busca pelo objeto da mensagem".

12 Rey-Debove (1971: 21), define microestrutura como "o conjunto das informações ordenadas de cada verbete, trazendo um esquema de informação constante para todos os verbetes, e que se leem horizontalmente após a entrada".
}

TradTerm, São Paulo, v. 34, outubro/2019, p. 27-47 
entrada, possui um recuo diferente do restante do verbete para que o consulente do glossário possa encontrar o termo que busca de forma mais clara e rápida.

\section{Análises e resultados}

Inicialmente geramos, através do AntConc, a lista de palavras de cada idioma, que pode ser vista, até a $10^{\mathrm{a}}$ posição, no Quadro 4:

Quadro 4: Dez primeiras palavras da lista de palavras do corpus de estudo em português e em francês.

\begin{tabular}{ccc}
\hline & Português & Francês \\
\hline $\mathbf{1}$ & de & de \\
$\mathbf{2}$ & a & la \\
$\mathbf{3}$ & do & à \\
$\mathbf{4}$ & 0 & est \\
\hline $\mathbf{5}$ & da & $l^{\prime}$ \\
$\mathbf{6}$ & $\mathrm{e}$ & le \\
$\mathbf{7}$ & é & et \\
$\mathbf{8}$ & que & les \\
$\mathbf{9}$ & solar & par \\
$\mathbf{1 0}$ & em & en \\
\hline
\end{tabular}

Nota-se que, naturalmente, as palavras mais frequentes de um corpus, seja qual for a sua temática, são palavras gramaticais, como artigos e preposições. Em português, temos a primeira palavra lexical na posição 9, "solar", seguida por "energia" na posição 12 e "radiação" na posição 15. Em francês, provavelmente devido ao maior número de preposições, a primeira palavra candidata a termo, rayonnement, aparece apenas na posição 21 , seguida por soleil na posição 25 , solaire, na 30 , e onde, na 31.

Para a coleta de termos, utilizamos a ferramenta Keyword list, que permite obter uma lista de candidatos a termo para cada idioma. Vejamos os primeiros candidatos a termo, segundo o AntConc: 
Quadro 5: Dez primeiras palavras da lista de palavras-chave do corpus de estudo em português e em francês.

\begin{tabular}{ccc}
\hline & Português & Francês \\
\hline $\mathbf{1}$ & solar & Rayonnement \\
$\mathbf{2}$ & energia & Soleil \\
$\mathbf{3}$ & ângulo & M \\
$\mathbf{4}$ & radiação & Solaire \\
\hline $\mathbf{5}$ & Sol & Onde \\
$\mathbf{6}$ & inclinação & Lumière \\
\hline $\mathbf{7}$ & solares & W \\
$\mathbf{8}$ & raios & Spectre \\
\hline $\mathbf{9}$ & módulo & Énergie \\
$\mathbf{1 0}$ & Figura & longueur \\
\hline
\end{tabular}

Cada candidato a termo foi analisado no Concordanciador e, a partir das linhas de concordância, separamos aqueles que podem ser considerados termos da área. Por exemplo, "Figura", a 10 $10^{\mathrm{a}}$ palavra de maior chavicidade em português, não é um termo, visto que faz parte das legendas de ilustrações dos textos que compõem o corpus. É, portanto, uma palavra frequente, mas não possui o status de termo da área. Ao final da análise prévia das duas listas de palavras-chave, obtivemos 74 candidatos a termo em português e 53 candidatos em francês.

A etapa seguinte deste trabalho se deu através da análise dos ganchos terminológicos de cada termo. A partir da confrontação dos ganchos, podemos verificar se dois termos de uma mesma língua são sinônimos e se dois termos de línguas diferentes são equivalentes. Vejamos os seguintes contextos retirados do corpus de estudo:

1: A radiação direta corresponde aos raios solares que chegam diretamente do Sol em linha reta e incidem sobre o plano horizontal com uma inclinação que depende do ângulo zenital do Sol.

2: Esses sensores captam uma faixa mais estreita do espectro solar e não conseguem distinguir a radiação direta da difusa.

3: A radiação solar incidente sobre os coletores solares é decomposta em duas componentes. A primeira é a radiação solar direta, definida como a fração da irradiação solar que atravessa a atmosfera sem sofrer alteração na sua direção original. A segunda componente corresponde à radiação difusa, (...). 
4: Notons au passage la différence entre le rayonnement direct, les rayons du soleil qui nous parviennent en ligne droite, et le rayonnement diffus, (...).

Podemos notar que "radiação direta" e rayonnement direct possuem o mesmo gancho de natureza ("raios solares" e rayons du soleil), de característica ("chegam diretamente do Sol em linha reta" e nous parviennent en ligne droit) e de oposição ("radiação difusa” e rayonnement diffus). Assim, ao verificarmos que os termos possuem os mesmos traços descritores, podemos considerá-los equivalentes, ou seja, termos que denominam um mesmo conceito. "Radiação solar direta", por sua vez, possui o mesmo gancho de oposição que os outros dois termos, sendo variante de "radiação direta" e equivalente de rayonnement direct. Os ganchos estão resumidos no Quadro abaixo:

Quadro 6: Comparação dos ganchos terminológicos dos termos "radiação direta", "radiação solar direta" e rayonnement direct.

\begin{tabular}{|c|c|c|c|}
\hline & $\begin{array}{l}\text { radiação } \\
\text { direta }\end{array}$ & $\begin{array}{c}\text { radiação solar } \\
\text { direta }\end{array}$ & $\begin{array}{c}\text { rayonnement } \\
\text { direct }\end{array}$ \\
\hline natureza & raios solares & $\begin{array}{l}\text { fração da irradiação } \\
\text { solar }\end{array}$ & rayons du soleil \\
\hline característica & $\begin{array}{l}\text { chegam diretamente } \\
\text { do Sol em linha reta } \\
\text { incidem sobre o plano } \\
\text { horizontal }\end{array}$ & $\begin{array}{l}\text { radiação solar incidente } \\
\text { sem sofrer alteração na } \\
\text { sua direção original }\end{array}$ & $\begin{array}{l}\text { nous parviennent en } \\
\text { ligne droite }\end{array}$ \\
\hline oposição & radiação difusa & radiação difusa & rayonnement diffus \\
\hline
\end{tabular}

O termo "albedo" tem seu equivalente no francês albédo. Vejamos ambos os termos em contexto:

5: 0 albedo, definido como a fração da radiação solar refletida e emitida pela vizinhança do coletor, como vegetação e construções, também é uma componente da radiação difusa.

6: Albédo: C'est la fraction d'un rayonnement incident diffusée ou réfléchie par un obstacle.

Dos contextos 5 e 6, é possível retirar os ganchos de natureza ("fração da radiação solar" e fraction d'un rayonnement) e de característica ("refletida e emitida pela vizinhança do coletor" e diffusée ou réfléchie par un obstacle), 
que, sendo similares, levam à conclusão de que "albedo" e albédo são equivalentes, como vemos no Quadro abaixo:

Quadro 7: Comparação dos ganchos terminológicos dos termos "albedo" e albédo.

\begin{tabular}{lll}
\hline & Albedo & Albédo \\
\hline natureza & $\begin{array}{l}\text { fração da radiação solar } \\
\text { componente da radiação difusa }\end{array}$ & fraction d'un rayonnement \\
característica & $\begin{array}{l}\text { refletida e emitida pela } \\
\text { vizinhança do coletor }\end{array}$ & $\begin{array}{l}\text { diffusée ou réfléchie par un } \\
\text { obstacle }\end{array}$ \\
\hline
\end{tabular}

Os exemplos acima ilustram o tipo de análise que foi realizada para cada termo em estudo. É importante observar que, para muitos termos, não é possível encontrar ganchos dentro dos textos que compõem nosso corpus de estudo. Nesses casos, utilizamos a Internet como corpus de apoio para uma pesquisa mais aprofundada sobre os conceitos e denominações envolvidos na área da Energia Solar Fotovoltaica e, mais especificamente, da Radiação Solar.

Por fim, vejamos um exemplo de parte do glossário, em que temos as unidades terminológicas "radiação solar", "radiação difusa", "radiação direta", "radiação global" e "raio solar" com suas variantes em português, equivalentes em francês e suas respectivas categorias gramaticais:

Quadro 8: Exemplo de parte do glossário no sentido do português para o francês.

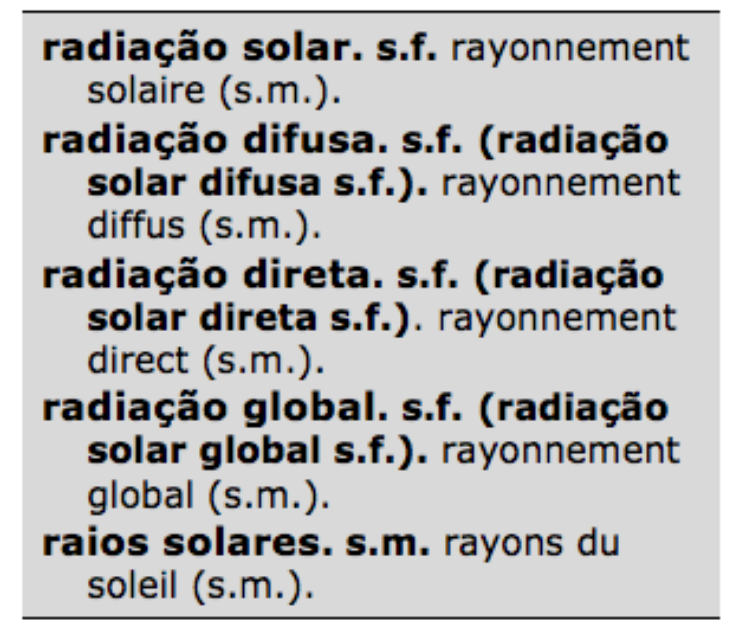




\section{Conclusão}

A pesquisa relatada neste artigo teve por objetivo identificar e estudar os termos da Radiação Solar para fins terminográficos. Para tanto, baseamonos na Teoria Comunicativa da Terminologia (CABRÉ 1999), nos ganchos terminológicos (DuBUC 1985) e utilizamos as ferramentas da Linguística de Corpus (ANTHONY 2014). Tratada, aqui, como uma subárea da Energia Solar Fotovoltaica, a Radiação Solar possui conceitos provenientes de outras áreas do conhecimento, como a Geografia, a Física e a própria Engenharia. Possivelmente por ser um domínio multidisciplinar, a Radiação Solar não possui, ainda, materiais bi e multilíngues que descrevam a sua terminologia.

Dentre os resultados obtidos, observamos uma grande quantidade de termos complexos, ou seja, termos formados por mais de uma lexia, tal como os exemplos já citados "radiação solar", "radiação difusa", "radiação direta" e "radiação global". Em geral, são termos que utilizam a denominação do hiperônimo (no caso, "radiação solar") para formar seus hipônimos (no caso, "radiação + [x]", em que x pode ser "difusa", "direta" ou "global"). Notamos, também, a existência de variação denominativa, ou seja, casos de sinonímia, tanto em português como em francês: albedo tem os equivalentes franceses albédo, albédo du sol e facteur de réflexion du sol; "espectro da radiação solar" é sinônimo de "espectro solar" e seus equivalentes são spectre solaire e spectre du soleil.

Assim, tendo em vista que muitos materiais de ESF possuem partes dedicadas à Radiação Solar e que os países Brasil e França possuem uma forte relação dentro do mercado fotovoltaico, este trabalho busca suprir a lacuna de produtos terminográficos da área no par linguístico português-francês. Dessa forma, esperamos contribuir com os estudantes e profissionais da Radiação Solar, assim como com tradutores de textos técnicos e científicos da área. 


\section{Referências}

Anthony, L. (2014). AntConc 3.4.3w. Tokyo: Waseda University, 2014. Disponível em: <http://www.laurenceanthony.net>. (18/01/2018).

AUBERT, F. H. Introdução à metodologia da pesquisa terminológica bilíngüe. 2 ed. São Paulo: FFLCH/CITRAT, 2001.

AULETE DigitAl. Raio. Disponível em: <http://www.aulete.com.br/raio>. Acesso em: 11 jun. 2018.

BAstianello, R. T. Terminologia da energia solar fotovoltaica para fins terminográficos: estudo baseado em corpus comparável (portuguêsfrancês). 2017. 378f. Dissertação (Mestrado) - Faculdade de Filosofia Letras e Ciências Humanas da Universidade de São Paulo, São Paulo, $2017 . \quad$ Disponível em: <http://www.teses.usp.br/teses/disponiveis/8/8146/tde-11122017190034/pt-br.php>. Acesso em: 01 maio 2018.

Berber SARDINHA, T.. Usando WordSmith Tools na investigação da linguagem. In: DIRECT Papers, 40. 1999. p. 1-20. Disponível em: <http://www2.lael.pucsp.br/direct/DirectPapers40.pdf>. Acesso em: 14 maio 2017.

- Linguística de Corpus. Barueri: Manole, 2004.

BeVILACQUA, C. R. Unidades Fraseológicas Especializadas: novas perspectivas para sua identificação e tratamento. Organon, Porto Alegre, v. 12, n. 26, p. 1-8, 1998.

CABRÉ, M. T. La Terminología: representación y comunicación. Barcelona: Institut Universitari de Lingüística Aplicada, 1999.

Dubuc, R. Manuel Pratique de Terminologie. 2 ed. Québec: Linguatech, 1985.

KRIEGER; M. FinatTo. M. Introdução à Terminologia: teoria e prática. 2 ed. São Paulo: Contexto, 2015.

KW SOLAR SOLUTIONS. Disponível em: <http://kwsolarsolutions.com/>. Acesso em: 5 jun. 2018.

LABOURET, A. et al. Cellules solaires: les bases de l'énergie photovoltaïque. 5 ed. Paris: Dunod, 2010.

MACIEL, A. M. B. Terminologia, linguagem de especialidade e dicionários. In: KRIEger, M. G.; MACIEL, A. M. B. (org.) - Temas de Terminologia. Porto Alegre/São Paulo: Ed. Universidade/UFRGS/Humanitas/USP, 2001. p. 39-46. 
PORTAL SOLAR. Tudo sobre a eficiência do painel solar. Disponível em: <https: / /www.portalsolar.com.br/tudo-sobre-a-eficiencia-do-painelsolar.html>. Acesso em: 04 jun. 2018.

A direção do painel solar. Disponível em: <https://www.portalsolar.com.br/a-melhor-direcao-do-painel-solarfotovoltaico.html>. Acesso em: 05 jun. 2018.

ReY-DeBove, J. Étude linguistique et sémiotique des dictionnaires français contemporains. The Hague, Paris: Mouton, 1971.

STORM BRASIL. Orientação solar. Disponível em: <http://www.strombrasil.com.br/orientacao-solar/>. Acesso em: 05 jun. 2018.

TAGnin, S. E. O. Glossário de Linguística de Corpus. In: TAGnin, S.; BeVILACQUA, C. Corpora na Terminologia. São Paulo: Hub Editorial, 2013, p. 215-219.

VILLALVA, M. G.; GAZOLI, J. R. Energia Solar Fotovoltaica: conceitos e aplicações. São Paulo: Érica, 2012.

WÜSTER, E. Introducción a la Teoría General de la Terminología y la Lexicografía Terminológica. Barcelona: Institut Universitari de Lingüística Aplicada, 1998.

ZILleS, R. et al. Sistemas Fotovoltaicos Conectados à Rede Elétrica. São Paulo: Oficina de Textos, 2012.

Recebido em: 05/03/2019

Aceito em: 27/06/2019

Publicado em outubro de 2019 